\title{
Clinical Evaluation, Functional Outcome and Complications of MicroEndoscopic Discectomy(MED) in Single or Double Level Lumbar Disc Herniation- A Retrospective Review of 156 Patients
}

\author{
Hitesh N. Modi ${ }^{1}$, Alkesh Rathod ${ }^{1}$, Utsab Shrestha ${ }^{1}$
}

\section{Abstract}

Introduction: Lumbar disc herniation $(\mathrm{LDH})$ is one of the most common causes for low back pain and related disabilities. Surgery is indicated in patients who do not respond to the conservative measures for at least 6 weeks or symptoms are worsened. Microendoscopic discectomy (MED) is a well-accepted minimally invasive surgical technique with similar results compared to open surgery. The purpose of this study was to evaluate the clinical outcome, functional improvement and analyze complications during MED.

Methods: A retrospective analysis was conducted in 156 patients who were operated for single or double level LDH using MED between 2016 and 2018. All patients were evaluated for pain and disability using visual analogue scale (VAS) and Oswestry disability index (ODI), respectively. Modified MabNab's criteria used to evaluate overall outcome of surgery. Operation time, estimated blood loss (EBL), hospital stay and time to return back to previous activities were evaluated. Complications and revisions were noted during follow-up to analyze clinical results. Paired t-test was used to evaluate statistical difference in VAS and ODI score during follow-up.

Results: All patients were followed up at 6 weeks, 3 months, 6 months, 1 year and yearly thereafter postoperatively. Average followup was $25.5 \pm 9.7$ months and average age was $45.0 \pm 12.7$ years. Average VAS scores improved significantly from preoperative $8.7 \pm 0.8$ to $2.0 \pm 1.1$ postoperatively $(\mathrm{p}<0.0001)$. Average preoperative ODI improved significantly from $53.8 \pm 6.1$ to $22.6 \pm 5.1$ postoperatively $(\mathrm{p}<0.0001)$. Both score were maintained at the final follow-up. The average time to return to previous activity level was $35.7 \pm 14.3$ days. Average operation time, EBL and hospital stay were $57.6 \pm 14.6$ minutes, $36.7 \pm 13.1 \mathrm{ml}$ and $2.4 \pm 0.7$ days, respectively. There were total $19(12.2 \%)$ complications and $12(7.7 \%)$ revisions in the series. Overall clinical outcome was excellent, good, fair and poor in $73.1 \%, 20.5 \%, 5.1 \%$ and $1.3 \%$ of cases using modified MacNab's criteria.

Conclusion: Study of 156 patients operated for single or double level LDH using MED has shown encouraging clinical results and functional outcome with similar complications reported in literature. However, less intraoperative blood loss, shorter hospital stay and early return to work are some of the advantages which favours its wide spread acceptability.

Keywords: Lumbar disc herniation; Microendoscopic discectomy; Clinical outcome; Complications.

Introduction

Lumbo-sacral back pain is a common and challenging clinical entity problem in pain management centre. Since its first description by Mixter and Barr [1] in 1934, lumbar disc

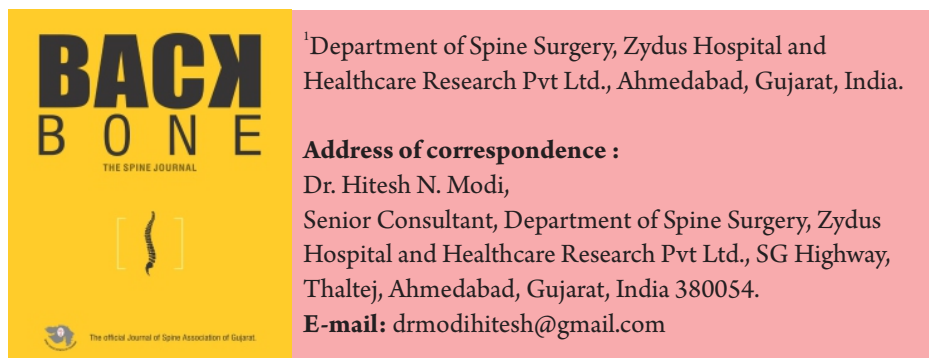

herniation (LDH) is one of the few abnormalities in the lumbar spine, were a clear relationship between the morphological alteration and pain seems to exist while pure mechanical compression was considered previously as a source of sciatica there is increasing evidence that chemical irritation of the nerve root plays an essential role perhaps even the most important role. The natural history of sciatica is favourable and typically resolve with conservative care which includes activity modifications, physical therapy, progressive exercise, nonsteroidal anti-inflammatory drugs, spinal injections, radio frequency ablations therapy and surgical intervention if not responded with conservative measures [2,3].

2021 (C) Back Bone: The Spine Journal (The Official Journal Of "Spine Association Of Gujarat") | Available on www.backbonejournal.com | DOI:10.13107/bbj.2021.v02i01.012 This is an Open Access article distributed under the terms of the Creative Commons Attribution Non-Commercial License (http://creativecommons.org/licenses/by-nc/3.0) which permits unrestricted non-commercial use, distribution, and reproduction in any medium, provided the original work is properly cited. 
Olmarker et al. have shown in an experimental animal model, that epidural application of autologous nucleus pulposus without compression of the cauda equina leads to a significant drop in the nerve conduction velocity of cauda equina [4]. Autoimmune response, microvascular changes and inflammatory reactions are potential causes of this phenomenon. Nucleus pulposus tissue has inflammatory properties, which leads to an intraneural oedema, a very important factor in the pathogenesis of sciatic pain. It is the natural history of the disease that the disc may subside on its own, the contained disc disappears due to the dehydration of the nucleus pulposus and the sequestered disc disappears due to phagocytosis by macrophages. Therefore, careful selection of the patient is a must before deciding for surgery. The most commonly involved surgical indications are intractable leg or/and back pain and significant functional impairment that have been unresponsive to conservative measures [2]. The absolute indication for lumbar herniated disc decompression is major motor weakness and cauda equina syndrome $[5,6]$. Diagnostic image appearance of the disc herniation can pinpoint the pathology but the decision for surgery is primarily dependent on the patient's clinical course rather than the size of the discherniation; not on the extruded disc material.

Traditional open surgery or micro discectomy which is known as open lumbar discectomy (OLD) is still the gold standard for surgical intervention for LDH. Role of surgical discectomy in improving clinical outcome is evidence based compared to the conservative treatement [7]. Lumbar microendoscopic discectomy (MED) is also a well-established procedure with low surgical morbidity and $90 \%$ success rates [8]. The standard surgical treatment of lumbar disc herniation has been open discectomy but there has been a trend towards minimally invasive procedures. MED for lumbar spine disc herniation is a well-known but developing field, which is increasingly spreading in the last few years $[9,10]$. It is becoming an effective alternative to standard open discectomy as almost all types of disc herniation can be treated with MED [11]. Present study was conducted to evaluate the clinical results, functional outcome and complications of micro endoscopic discectomy (MED) in cases lumbar disc herniation.

\section{Material and Methods}

We performed a retrospective analysis of patients who were operated for single or double level microendoscopic discectomy (MED) for lumbar disc herniation between 2016 and 2018. All patients had backache and radicular pain in lower limb due to prolapsed intervertebral disc with failure of conservative treatment presenting to our center.

A total of 156 patients were selected with following inclusion criteria: (1) The patient with predominantly unilateral or bilateral radicular leg pain and not improving symptomatically for at least 6 weeks of conservative treatment. (2) Patients with significant neurological deficits in form of weakness in affected myotome. (3) Patients with severe radicular pain or worsening symptoms. (4) Patients with cauda equina syndrome. (5) Patient's symptoms and MRI were correlating with each other; i.e. LDH on MRI with clinically radicular pain in the affected nerve root with herniated side. (6) Patient with single or double level disc problem. The patients were ineligible if they met certain exclusion criteria: (1) Patients with multiple level disc prolapse (2 or more levels). (2) Previous spine surgery. (3) Patients with spinal canal stenosis or instability. (4) Patients with disc lesion along with spondylolysis or spondylolisthesis. (5) Patients who are medically unfit for surgery.

All procedure of microendoscopic lumbar discectomy (MED) performed using tubular retractors as described by Smith and Foley [12] by a single surgeon under general anesthesia (Fig. 1). Postoperatively, patients were allowed to turn in bed and mobilized within 24 hours. Patient were again examined for severity of back pain and radicular pain in lower limbs and VAS score and ODI score for this were noted, neurological function was closely monitored after surgery. The first postoperative dressing was done after 24 hours. Patients were followed up at an interval of 6 weeks, 3 months, 6 months, 1year and yearly thereafter.

All patietns were evaluated clinically using pain and functionality criteria by Oswestry Disability Index (ODI) and visual analogue score (VAS), respectively. ODI Scores of 0$20 \%, 21-40 \%, 41-60 \%, 61-80 \%$ and $>80 \%$ were classified as minimal, moderate, severe, crippled and severely crippled (functional) disability, respectively. Similarly VAS scales of 0 , $1-2,3-6,7-8$ and $9-10$ were conseidered as no distress,

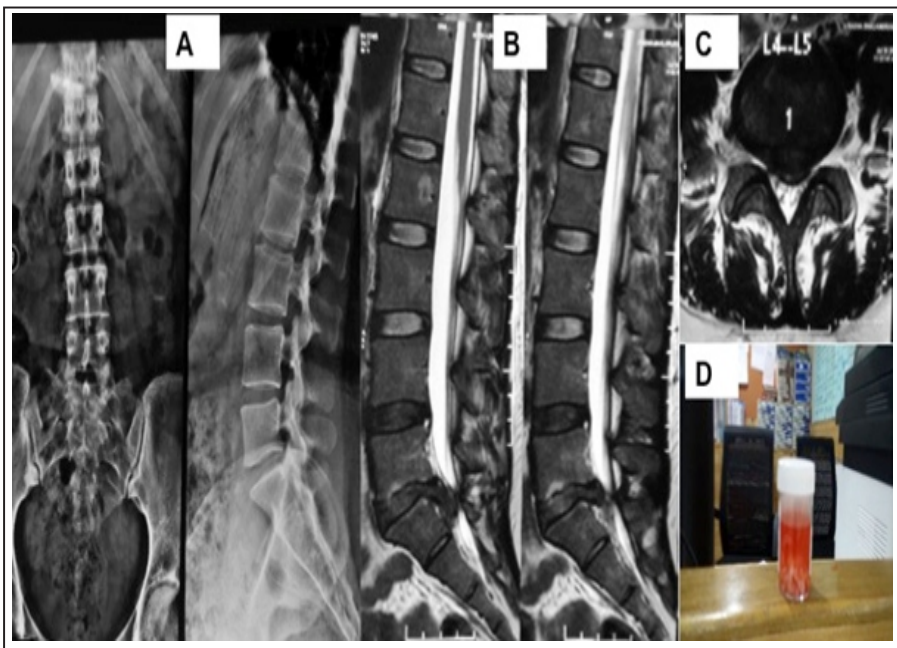

Figure 1: (A) AP and lateral $x$-ray images, (B) sagittal T2 image and $(C)$ axial T2 image of MRI of lumbar spine in a 33-year old female showing large centrally down-migrated sequestrated disc at L4-5 which was operated with MED with removal of (D) multiple pieces of herniated disc fragments. 
annoying, uncomfortable, dreadful, horrible and agonizing pain category, respectively. Preoperative and postoperaitve VAS and ODI scores were compared using paired t-test for the clinical significance. Overall results were also evaluated using MacNab's criteria at the follow-up with excellent, good, fair and poor outcome. Return to work was also considered an important criteria to evaluate our results. Inraoperative and postoperative complications were evaluated in detail.

\section{Results}

Of 156 patients ( 83 males and 73 females) in this study, their age, sex, levels of disc herniation are described in table 1 . The average age of study population was $45.0 \pm 12.7$ years (range, 13 80 years). The average follow-up was $25.5 \pm 9.7$ months (range, 12-46 months). There were 5, 14, 43, 37, 41, 12 and 4 patients with age $<20,21-30,31-40,41-50,51-60,61-70$ and $>71$ years, respectively. There were $89.1 \%(\mathrm{n}=139)$ and $10.9 \%(\mathrm{n}=17)$ of the discs at single and double level, respectively. Similarly $57.1 \%(n=89)$ and $42.9 \%(n=67)$ discs were operated from left and right sides, respectively. The levels are described in table 2 . There were 125 (80.1\%) and 31 (19.9\%) patients had paracentral and central disc herniation, respectively (Fig. 2-3). Of them $35(22.4 \%), 88(56.4 \%)$ and $33(21.2 \%)$ patients had

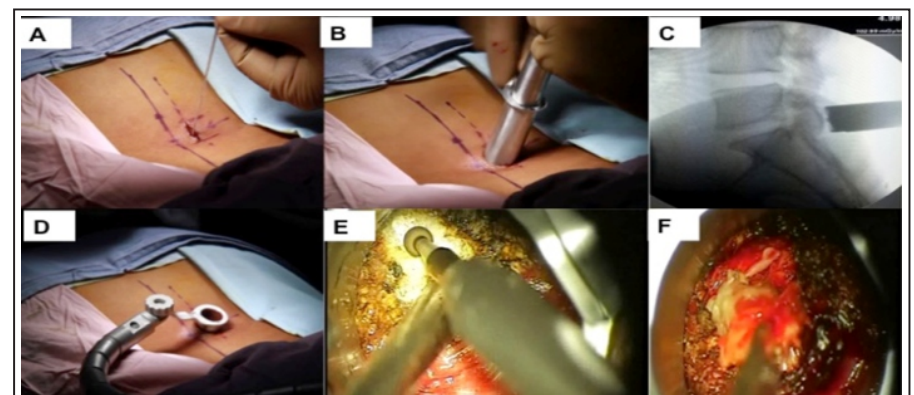

Figure 2: Surgical procedure for MED. (A) $2 \mathrm{~cm}$ skin incision around guide wire after confirming location, (B) insertion of serial dilators and final retractor tube, $(\mathrm{C})$ confirming level of retractor tube under carm, (D) final positioning of retractor tube before microscope, (E) use of high-speed burr for thinning out lamina and creating fenestration flavotomy and (F) removal of herniated disc tissues after gently retracting dura and root medially under microscope.

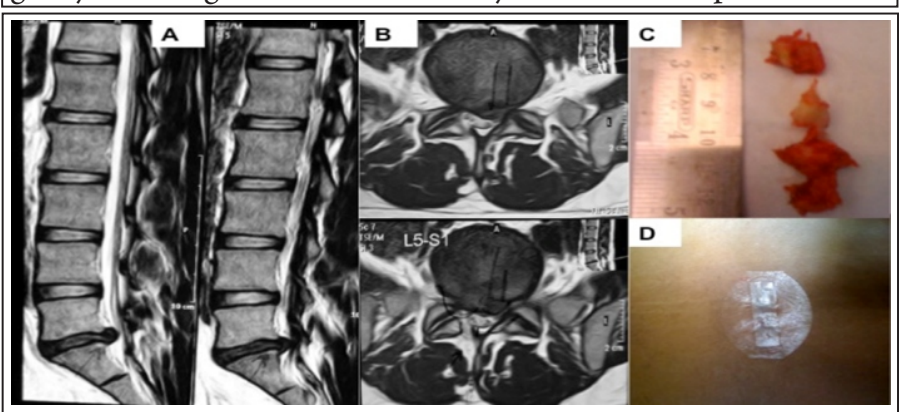

Figure 3: Figure showed (A) T2 sagittal image and (B) T2 axial images on lumbar MRI in a 28-year old male patient, which suggests large paracentral extruded disc at L5S1 on left side. Patient was operated with MED with removal of (C) large disc fragments and (D) final closure of wound subcuticularly. bulging, protrusion and extrusion/sequestration, respectively (Table 3).

Average operation time and intraoperative estimated blood loss (EBL) were $57.6 \pm 14.6$ minutes and $36.7 \pm 13.1 \mathrm{ml}$, respectively. Similarly Average hospital stay was $2.4 \pm 0.7$ days (Table 4). All patients had significant improvement clinically in terms of their VAS and ODI scores (Table 5). Their average VAS scores improved from preoperative $8.7 \pm 0.8$ to 3-month postoperatively $2.0 \pm 1.1$ ( $\mathrm{p}<0.0001$, paired $\mathrm{t}$-test), which was also maintained at the final follow-up at $1.6 \pm 0.7(\mathrm{p}<0.0001$, paired t-test). Similarly average preoperative ODI scores improved from 53.8 46.1 significantly to 3 -month postoperatively to $22.6 \pm 5.1$ ( $\mathrm{p}<0.0001$, paired $\mathrm{t}$-test), which was maintained at the final follow-up at $18.7 \pm 4.8(\mathrm{p}<0.0001$, paired $\mathrm{t}$-test). The average time to return to their previous activity level was $35.7 \pm 14.3$ days; of which $14.1 \%$, $57.1 \%$, $21.8 \%, 4.5 \%$ and $1.3 \%$ patients returned to their previous work in $<3$ weeks, 3-6 weeks, 6-9 weeks, 9-12 weeks and $>12$ weeks of their surgery (Table 6). Two patients who had intraoperative dural tear and lumbar instability did not return to their activity even after one year. Using modified MacNab's criteria there were 114 (73.1\%), 32 (20.5\%), 8 (5.1\%) and 2 (1.3\%) patients had excellent, good, fair and poor clinical outcome (Table 7).

\begin{tabular}{|c|c|}
\hline Table 1: Shows demographics of patients. & \\
\hline Total Number of Patients & 156 \\
Male & 83 \\
Female & 73 \\
\hline Average Age (Years) & $45.0 \pm 12.7$ \\
Single Level Disc & 139 \\
\hline Double Level Disc & 17 \\
\hline Average Follow-up (Months) & $25.5 \pm 9.7$ \\
\hline
\end{tabular}

Table 2: Shows level of disc herniations in patients.

\begin{tabular}{|c|c|c|}
\hline Disc Level & \multicolumn{2}{|c|}{ Side of Decompression } \\
\hline L3-4 & Right & Left \\
\hline L4-5 & 3 & 2 \\
\hline L5S1 & 39 & 44 \\
\hline L3-4, L4-5 & 16 & 35 \\
\hline L4-5, L5S1 & 1 & 0 \\
\hline L3-4, L5S1 & 7 & 8 \\
\hline Total & 1 & 0 \\
\hline \hline
\end{tabular}

Table 3: Suggests types of disc herniation in the study population.

\begin{tabular}{|c|c|c|}
\hline Type of Disc Herniation & Central Disc & Paracentral Disc \\
\hline Bulging & 6 & 29 \\
\hline Protrusion & 17 & 71 \\
\hline Extrusion/Sequestration & 8 & 25 \\
\hline Total & 31 & 125 \\
\hline
\end{tabular}

08 | Back Bone: The Spine Journal | Volume 2 | Issue 1 | April-September 2021 | Page 06-11 
Table 4: Shows average operation time ( $\mathrm{min}$ ), estimated blood loss $(\mathrm{mL})$, hospital stay (days) and time to return back to work (days) in patients.

\begin{tabular}{||c|c|c||}
\hline & Average & SD \\
\hline Operation Time (Minutes) & 57.6 & 14.8 \\
\hline Estimated Blood Loss (mL) & 36.7 & 13.1 \\
\hline Hospital Stay (Days) & 2.4 & 0.7 \\
\hline Return to Work (Days) & 35.7 & 14.3 \\
\hline
\end{tabular}

Table 5: Shows clinical outcome scores by visual analogue scale for pain and Oswestry disability index at preoperative, 3-month postoperative and at final follow-up in study population.

\begin{tabular}{|c|c|c|c|c|}
\hline \multicolumn{2}{|c|}{ Clinical Scores } & Average & SD & $P$ value \\
\hline \multirow{3}{*}{ VAS Scores } & Preoperative & 8.7 & 0.8 & \\
\hline & 3-month FU & 2 & 1.1 & $<0.0001$ \\
\hline & Final FU & 1.6 & 0.7 & $<0.0001$ \\
\hline \multirow{3}{*}{ ODI Scores } & Preoperative & 53.8 & 6.1 & \\
\hline & 3-month FU & 22.6 & 5.1 & $<0.0001$ \\
\hline & Final FU & 18.7 & 4.8 & $<0.0001$ \\
\hline
\end{tabular}

Table 6: Suggests numbers of patients with their percentage required to return back to previous work after surgery.

\begin{tabular}{|c|c|c|}
\hline Return to Work (days) & Patients (n) & Percentage (\%) \\
\hline < 3weeks & 22 & 14.1 \\
\hline 3-6 weeks & 89 & 57.1 \\
\hline 6-9 weeks & 34 & 21.8 \\
\hline 9-12 weeks & 7 & 4.5 \\
\hline >12 weeks & 2 & 1.3 \\
\hline Not Return & 2 & 1.3 \\
\hline Total & 156 & 100 \\
\hline
\end{tabular}

Table 7: shows patients' outcome using MacNab's criteria in to excellent, good, fair and poor outcome.

\begin{tabular}{|c|c|c|}
\hline MacNab's Criteria & Patients (n) & Percentage (\%) \\
\hline Excellent & 114 & $73.10 \%$ \\
\hline Good & 32 & $20.50 \%$ \\
\hline Fair & 8 & $5.10 \%$ \\
\hline Poor & 2 & $1.30 \%$ \\
\hline Total & 156 & $100 \%$ \\
\hline
\end{tabular}

Regarding complications, 19 patients developed complications in the series comprising $12.2 \%$ (Table 8 ). There were $4,3,3,2,2,2,1,1$, and 1 patient who developed complications in form of same level-same side recurrent disc herniation, persistent numbness/low back pain, instability at operative level, radicular symptoms, same level-opposite side recurrent disc herniation, other level disc herniation, intraoperative dural tear, wound infection and postoperative hematoma, respectively. There were 12 (7.7\%) patients who required revision surgery; out of these 12 the one with dural tear during surgery had undergone for conversion to open surgery for the repair. This patient had postoperative caudaequina syndrome, which recovered with minimal disability within one year postoperatively. However, patient could not return to her previous activity level. Rest 11 patients who underwent for revision surgeries are shown in table 8 and they returned to their previous work after successful outcome. Similarly one patient who developed instability postoperatively at 9 months after surgery could not return to her activity level. She was advised for revision surgery, however, she did not agree for it. Other six conservatively treated patients returned to previous work once clinical improvement happened.

\section{Discussion}

Low back pain due to lumbar disc herniation is a prominent cause of morbidity in labourers and persons working in industries and carries with it severe economic consequences. Out of various forms of management being offered, literature is still inconsistent with their predictive value in sciatica treatment [2]. In some studies examining MRI, the size and shape of the disc protrusion appeared to be able to predict the success of the treatment more accurately than did the clinical finding [13]. Other indicated that the integrity of the annulus fibrosus may correlate with clinical outcomes [14]. It is also reported that $80 \%$ of patients with lumbar disc herniations can be treated with conservative therapy [15]. Surgery is indicated only in those patients who have severe clinical symptoms affecting their activities, neurological signs and symptoms or

\begin{tabular}{|c|c|c|c|c|c|c|}
\hline Table 8: Shows type and & numbers of complications with their further treatment options. \\
\hline Complications & Total (n) & $\begin{array}{r}\text { Time of Appearance of Complication } \\
\text { Intraoperative }\end{array}$ & $\mathbf{3}$ months & $\mathbf{3 - 1 2}$ months & >12 months & Revisions* \\
Numbness/LBP & 3 & 0 & 1 & 1 & 1 & 0 \\
Radicular Symptoms & 2 & 0 & 0 & 1 & 1 & 0 \\
Recurrent PID (Same side) & 4 & 0 & $3 *$ & 0 & $1 *$ & 4 \\
Recurrent PID (Opp side) & 2 & 0 & 1 & & $1 *$ & 1 \\
Other level PID & 2 & 0 & 0 & $1 *$ & $1 *$ & 2 \\
Instability & 3 & 0 & $1 *$ & 1 & $1 *$ & 2 \\
Dural Tear & 1 & $1 *$ & 0 & 0 & 0 & 1 \\
Wound Infection & 1 & 0 & $1 *$ & 0 & 0 & 1 \\
Hematoma & 1 & 0 & $1 *$ & 0 & 0 & 1 \\
Total & 19 & 1 & 8 & 4 & 6 & 12 \\
\hline
\end{tabular}

09 | Back Bone: The Spine Journal | Volume 2 | Issue 1 | April-September 2021 | Page 06-11 
do not improve with conservative treatement; and operation should be considered as the only one effective method $[6,16]$. In our patients we have initially considered conservative treatment in all patients in form of anti-inflammatory medications and physiotherapy. We considered surgery when conservative treatment failed to improve clinical condition of patients or worsened their symptoms with/without neurological deficit. We have evaluated clinical outcome of 156 patients operated with MED for single or double level lumbar disc herniation, which suggests an operative technique should be considered if conservative treatment is not effective or symptoms are worsening for the better outcome.

Perez-Cruet et al. reported their outcome in 150 consecutive patients operated with MED [17]. Their technique consisted inserting an video endoscope through the tubular retractor and performing surgery under imaging of video monitor. However, following modificatios in MED techniques, we performed surgeries under microscopic vision through the same tubular retractor. They have reported clinical outcomes using a modified MacNab criteria, which revealed $77 \%$ of patients had excellent, $17 \%$ had good, $3 \%$ had fair, and $3 \%$ had poor outcomes. Similarly we also found $73.1 \%, 20.5 \%, 5.1 \%$ and $1.3 \%$ patients had excellent, good, fair and poor outcome, respectively. They have notice complications primarily included dural tears, which occurred in 8 patients (5\%) and were seen early on in the patient series. In our series we have reported all list complications in detail which can occur in MEDs and had occurred in our series. According to type and site of disc prolapse, patients are separated into central and paracentrally located herniation groups. Palea et al. in their article of selecting tubular or endoscopic discectomy procedure based on disc size and locations noted that tubular and endoscopic systems have evolved over the period, many different types of smaller herniated and partially degenerated discs can also be effectively and safely de-bulked or removed using these minimally invasive procedures. As these procedures keep evolving, removal of large or migrated disc fragments is more routine [18]. Similarly in our series we have performed MED procedure in both paracenral and central disc herniations with all variety such as, bulging, protrusion and extrusion/sequestration with up and down-migrated discs. The results are universal in any size, type and level of the disc herniation in our series, which indicated that we can use tubular retractors safely with equivallent clinical outcome as reported byZhou et al [19].

The advantages of MED over open discectomy include small incision, less intraoperative blood loss, early ambulation, short hospital stay and early return to work and thus less cost of treatment $[10,11,17,20]$. The mean surgical time was less than one hour in our series which was similarly reported by Jhala et al [21]. and Kulkarni et al [22]. Additionally the average intraoperative blood loss and hospital stay was $36.7 \pm 13.1 \mathrm{~mL}$ and $2.4 \pm 0.7$ days, respectively, which is similar to the published literature reports. The time to return to their previous activity level $35.7 \pm 14.3$ days. It was intersting to note that $14.1 \%, 57.1 \%$ and $21.8 \%$ (total $93 \%$ ) patients resumed their activities in less than 3 weeks, 3-6 weeks and 6-9 weeks time, respectively. It proved that majority of patient return to their activity level in around 2-month time postoperatively.

In terms of return to work, in our study it was 35.7 days as compared to other study by Than et al. in which return to work was 80 days [23]; earlier in cases of younger population. Yadav et al. reported that MED entailed shorter hospital stay, less morbidity, and earlier return to work less anesthetic exposure less blood loss, less intraoperative time comparing to open discectomy. MED is a safe and effective alternative to conventional discectomy for the patients with LDH [24]. Bookwalter et al. reported that $40 \%$ of their patients returned to work in fewer than 5 weeks proving its cost-effectiveness [25]. Caspar et al. reported a mean return-to-work time of 18.6 weeks [26] and Perez-Cruet at al. reported a mean return-towork time of 17.6 days [17]. In our series $93 \%$ of patients resumed their activities with in 9 weeks of surgery suggests early return to work, and thereby, less economic loss.

Literature mentioned various complications during MED surgery such as, CSF leak, nerve root injury, infection, recurrence of disc herniation, instability, wrong level surgery, etc. Teli et al. reported that dural tears, root injuries and recurrent herniations were significantly more common in MED [27]. Wound infections were similar in all kinds of discectomy. Garg et al. found, in their initial series of 30 patients, 5 dural leaks which contributed to learnig experience [28]. In our series we found only one dural tear at ligher level discectomy due to sudden slip of burr. This patient needed open repair as tear was large. As we also had more number of tears in our initial expereice which was not a part of this study. Recurrent discherniation was the most common complication in our series as it can occur at any time [22]. Kulkarni et al. reported, in their series of 188 patients operated with MED, that 4, 3, 1 and 1 patient underwent for revision surgery due to residual disc fragment, recurrent disc herniation, wring level surgery and wound infection, respectively [22]. We also found similar revision surgeries in our series comprising $7.7 \%$. On the other hand Overdevest et al. reported reoperation rate of $18 \%$ with MED compared to $13 \%$ in open discectomy [29], therefore we believe that reoperation can occur in both types of cases due to various reasons which should not be the reason of choosing one technique over the other.

The average follow-up period was $25.5 \pm 9.7$ months (range, 12 46 months) was medium term, which may be one of shortcomings in our study. However, minimum follow-up of 12 months and 156 patient populations with inclusion of central 
and paracentral disc herniation types are positive factors in the study. We believe that further studies with even larger number of patient population with long-term follow-up would further add in depth knowledge regarding evaluation of MED. We plan to continue this study and add more number of patients in the current study group to produce more information.

\section{References}

1.MIXTER, W.J. and J.S. BARR, Rupture of the Intervertebral Disc with Involvement of the Spinal Canal. New England Journal of Medicine, 1934. 211(5): p. 210215.

2. Hahne, A.J.J.J.Ford, and J.M.McMeeken, Conservative management of lumbar disc herniation with associated radiculopathy: a systematic review. Spine (Phila Pa 1976), 2010.35(11):p.E488-504.

3. Gibson, J.N. and G. Waddell, Surgical interventions for lumbar disc prolapse: updated Cochrane Review. Spine (Phila Pa 1976), 2007.32(16):p. 1735-47.

4. Olmarker, K., R. Størkson, and O.G. Berge, Pathogenesis of sciatic pain: a study of spontaneous behavior in rats exposed to experimental disc herniation. Spine (PhilaPa 1976), 2002.27(12):p.1312-7.

5. Shapiro, S., Cauda equina syndrome secondary to lumbar disc herniation. Neurosurgery, 1993.32(5): p.743-6; discussion 746-7.

6. Shapiro, S., Medical realities of cauda equina syndrome secondary to lumbar disc herniation. Spine (PhilaPa 1976), 2000.25(3): p. 348-51; discussion 352.

7. Gibson, J.N., I.C. Grant, and G. Waddell, The Cochrane review of surgery for lumbar disc prolapse and degenerative lumbar spondylosis. Spine (Phila Pa 1976), 1999. 24(17): p. 1820-32.

8. Kahanovitz, N., K. Viola, and J. Muculloch, Limited surgical discectomy and microdiscectomy. A clinical comparison. Spine (Phila Pa 1976), 1989. 14(1): p. 79-81.

9. Katayama, Y., et al., Comparison of surgical outcomes between macro discectomy and micro discectomy for lumbar disc herniation: a prospective randomized study with surgery performed by the same spine surgeon. J Spinal Disord Tech, 2006. 19(5):p.344-7.

10. Nakagawa, H., et al., Microendoscopic discectomy (MED) for lumbar disc prolapse.JClin Neurosci, 2003.10(2):p.231-5.

11. Rasouli, M.R., et al., Minimally invasive discectomy versus microdiscectomy/open discectomy for symptomatic lumbar disc herniation. Cochrane Database Syst Rev, 2014(9): p. Cd010328.

12. Foley, K.T., Microendoscopic discectomy. Techniques in neurosurgery, 1997. 3: $p$. 301-307.

13. Hancock, M.J., et al., Diagnostic Accuracy of the Clinical Examination in Identifying the Level of Herniation in Patients with Sciatica. Spine, 2011.36(11): p.E712-E719.

14. Acaroglu, E.R., et al., Degeneration and aging affect the tensile behavior of human lumbar anulusfibrosus. Spine (Phila Pa 1976), 1995. 20(24): p. 2690-701.

15. Gautschi, O.P., G. Hildebrandt, and D. Cadosch, [Acute low back pain--assessment

\section{Conclusion}

Our study of 156 patients who were operated for single or double level lumbar disc herniation using MED technique has shown encouraging clinical results and functional outcome with similar complications reported in literature. However, less intraoperative blood loss, shorter hospital stay and early return to work are some of the advantages which favours its wide spread acceptability in the surgical treatment of lumbar disc herniation. and management].Praxis (Bern 1994), 2008.97(2): p.58-68.

16. Rothoerl, R.D., C. Woertgen, and A. Brawanski, When should conservative treatment for lumbar disc herniation be ceased and surgery considered? Neurosurg Rev, 2002.25(3): p.162-5.

17. Perez-Cruet, M.J., et al., Microendoscopic lumbar discectomy: technical note. Neurosurgery, 2002.51(5 Suppl):p.S129-36.

18. Palea, O., M. Granville, and R.E. Jacobson, Selection of Tubular and Endoscopic Transforaminal Disc Procedures Based on Disc Size, Location, and Characteristics. Cureus, 2018.10(1):p.e2091-e2091.

19. Zhou, Y., et al., Clinical experience and results of lumbar microendoscopic discectomy: a study with a five-year follow-up. Orthopaedic surgery, 2009. 1(3): p.171-175.

20. Tullberg, T., J. Isacson, and L. Weidenhielm, Does microscopic removal of lumbar disc herniation lead to better results than the standard procedure? Results of a oneyear randomized study. Spine (Phila Pa 1976), 1993.18(1):p.24-7.

21. Jhala, A. and M. Mistry, Endoscopic lumbar discectomy: Experience of first 100 cases. Indian journal of orthopaedics, 2010.44(2): p.184-190.

22. Kulkarni, A.G., A. Bassi, and A. Dhruv, Microendoscopic lumbar discectomy: Technique and results of 188 cases. Indian journal of orthopaedics, 2014. 48(1): p. 81-87.

23. Than, K.D., et al., How to predict return to work after lumbar discectomy: answers from the NeuroPoint-SD registry. JNeurosurg Spine, 2016.25(2): p. 181-6.

24. Yadav, R.I., L. Long, and C. Yanming, Comparison of the effectiveness and outcome of microendoscopic and open discectomy in patients suffering from lumbar disc herniation.Medicine (Baltimore), 2019.98(50): p.e16627.

25. Bookwalter, J.W., 3rd, M.D. Busch, and D. Nicely, Ambulatory surgery is safe and effective in radicular disc disease. Spine (Phila Pa 1976), 1994. 19(5): p. 526-30.

26. Caspar, $W$., et al., The Caspar microsurgical discectomy and comparison with a conventional standard lumbar disc procedure. Neurosurgery, 1991. 28(1): p. 7886; discussion 86-7.

27. Teli, M., et al., Higher risk of dural tears and recurrent herniation with lumbar micro-endoscopic discectomy. Eur Spine J, 2010.19(3): p.443-50.

28. Garg, B., U.B. Nagraja, and A. Jayaswal, Microendoscopic versus open discectomy for lumbar disc herniation: a prospective randomised study. J Orthop Surg (Hong Kong), 2011.19(1):p.30-4.

29. Overdevest, G.M., et al., Tubular discectomy versus conventional microdiscectomy for the treatment of lumbar disc herniation: long-term results of a randomised controlled trial.J Neurol Neurosurg Psychiatry, 2017.88(12): p. 1008-1016.
Conflict of Interest: NIL Source of Support: NIL

\section{How to Cite this Article}

Modi HN, Rathod A, Shrestha U | Clinical Evaluation, Functional Outcome and Complications of MicroEndoscopic Discectomy(MED) in Single or Double Level Lumbar Disc Herniation- A Retrospective Review of 156 Patients | Back Bone: The Spine Journal | April-September 2021; 2(1):06-11.

11 | Back Bone: The Spine Journal | Volume 2 | Issue 1 | April-September 2021 | Page 06-11 